American Journal of Economics and Business Administration 2 (2): 172-178, 2010

ISSN 1945-5488

(C) 2010 Science Publications

\title{
Treks'n Rapids: Identifying Motivational Factors for Adventure Sports
}

\author{
${ }^{1}$ Kshitij Saxena and ${ }^{2}$ A.K. Dey \\ ${ }^{1}$ FORE School of Management, B-18, Qutab Institutional Area, New Delhi-110016, India \\ ${ }^{2}$ Supply Chain and Operations Management, Birla Institute of Management Technology, \\ Plot No. 5, Knowledge Park II, Greater Noida, UP-201306, India
}

\begin{abstract}
Problem statement: Treks'n Rapids, a leading adventure sports and human resource enrichment company in India, wanted to identify main motivational factors of attraction towards adventure sports among youths of National Capital Region. Objective was to improve the effectiveness of integrated marketing communications strategy. Adventure sports are categorized into four classes: (1) mountain sports; (2) extreme sports like bungee jumping and free fall; (3) rafting and kayaking; (4) paragliding, sky diving and skiing. A total of fifteen motivational factors have been identified with the help of literature review and an exploratory study. These are: Thrill, Requires zeal/energy, Spells status, Builds confidence, Helps in personality development, Instills self-belief, Creates unique identity, Is a stress buster, Helps in goal-setting, Is challenging, Requires toughness, Builds sense of achievement, Is a unique experience, It is fun/adventure and Improved technology has reduced risk. Approach: A questionnaire was created and sent to over 500 people online. Through word of mouth people were encouraged to visit the website and respond to the questionnaire. Fifty-seven responses were obtained. These were analyzed using SPSS. Results: Only two factors were extracted. First all the 57 responses were analyzed as a whole to find out the main motivational factors. Next each of the four individual categories of adventure sports was separately analyzed and results were found to be highly consistent. Two composite variables that emerged are labeled as: (1) characteristics of the adventure sports encompassing: thrill, challenge, fun, toughness and zeal required; (2) characteristics of the self like: building confidence, personality development, sense of achievement, status, self-belief and help in goal setting. Resultant factors were used to discriminate respondents based on gender and spend. In both the cases more than $73 \%$ of original grouped cases were found to be correctly classified. Conclusion: Findings of this study will help a firm engaged in adventure sports in developing an effective integrated marketing communication strategy by fine tuning messages in their communication.
\end{abstract}

Key words: Adventure sports, perception mapping, motivational factors, mountain sports, factor analysis

\section{INTRODUCTION}

Adventure sports have obtained both significant profile and following during recent years. The definition of what constitutes an adventure sport is fluid, as new sports are introduced on a regular basis; all adventure sports tend to produce a profound surge of excitement in the athlete (an "adrenalin rush"), while requiring the athlete to assume significant physical risks. As a general rule, an adventure sport will require the athlete to perform at a high rate of speed, where the athlete is subject to significant effects of gravity, or where the athlete is exposed to special dangers due to the performance of a stunt with limited, or no, safety equipment.

Another compelling distinction between the definition of conventional sport and the adventure sports category is the lesser importance in the adventure sports of the classic pillars of physical fitness (endurance, muscle strength, speed, power and flexibility). The successful adventure athlete must build significant levels of all around fitness to participate in sports such as rock climbing, which engages every muscle in the body, that same fitness level, while useful, is not essential to participate in adventure sports such as a sky diving or motocross.

Corresponding Author: A.K. Dey, Supply Chain and Operations Management, Birla Institute of Management Technology, Plot No. 5, Knowledge Park II, Greater Noida, UP-201306, India Tel: 09810387104/+91-120-2323001 to 10 Fax: +91-120-2323022/25 
The adventure sports tend to place less emphasis upon formal coaching and training, due to their appeal to individual athletes. It is both a hallmark and an attraction of the extreme sports that a novice to the particular sport can participate very soon after their introduction to the activity.

Another distinguishing feature regarding the sports included in the adventure sports category is the nature of the equipment required by the athlete. Most of the equipment is relatively simple to operate, such as a skateboard, bungee cord, or wakeboard; in some sports, a simple piece of equipment is used in conjunction with a mechanized device, such as a tow boat or other transportation.

Adventure sports are played in the air, along the surface of the earth and on and below the surface of the water. Within the adventure sports classification, activities can be further sub-divided into two groups: Adventure sports that are inherently extreme in their execution and those adventure sports that are made extreme by the adaptation of an additional feature.

For this study adventure sports are categorized into four classes: (1) mountain sports; (2) extreme sports like bungee jumping and free fall; (3) rafting and kayaking; (4) paragliding, sky diving and skiing.

Treks'n Rapids has been in the business of adventure sports for past seven years catering to different needs and aspirations of people by providing them best of outdoor activities in India and abroad. But today, in tough time of recession, it faces major problem of understanding their changing needs and desires. Today Treks'n Rapids faces a higher level of competition from other adventure sports firms. Challenge before the company is to attract more participants while keeping tight control on costs. The dilemma facing the company is how to market adventure sports that would lead to increase in sales and customers and at the same time achieve it with the limited resources of money and time. What attracts people to adventure sports? What motivates the young adults to take up adventure sports? The company has to take a quick decision before it loses out existing and new customers to competitors.

Treks'n Rapids reinvented its online approach few years back and has been promoting the company in various categories such as:

- Corporate experiential learning: OUTPERFORM: Learning by doing high impact, innovative outbound training programmes at self owned and third party campuses, across India and Internationally. Top grade and highly experienced In House faculty and proprietary modules
- Outdoor leadership programmes for children: CHIPMUNKS: Confident ever after out-of-thebox, innovative and confidence building summer camps and customized programmes for children

- Adventure gear: HUCKFINN: An initiative of Treks'n Rapids that will manufacture and deliver the adventure sports equipment at a very low price and meeting international standard. Currently the range will include: White water rafting equipment, trekking and camping gear, climbing gear, aero sports equipment and specialty gears such as artificial rock climbing walls and ceramic holds, Zorb and all terrain vehicles. Visit online store

- Certificate courses in adventure sports: TNR adventure academy: Short term certificate programmes in: Rock climbing, survival techniques and leave no trace, paragliding scuba diving

- Community building initiative: Adventure bug club

Need for the study at trek's and rapids: In general, motivation is the need that drives an individual to act in a certain way to achieve the desired satisfaction. In particular, many different reasons and motivational factors compel people to take to adventure sports. These forces are perceived as being able to decrease the condition of tension towards adventure sports felt by the individual. The reduced state of tension then gives way to the necessity that encourages an action or attitude. Although the decision to satisfy needs may rely on other psychological variables, in reality, all human behavior is motivated. Motivations can be the result of internal and external stimuli. Internal stimuli arise from personal needs that can be physiological, social, egocentric, safety and self-actualization. External stimuli result from publicity and promotion. Motivations around adventure sports can be personal such as building confidence, personality development, sense of achievement, status, self-belief and help in goal setting. Motivations could also be due to the characteristics of the adventure sports encompassing: thrill, challenge, fun, toughness and zeal required.

Based on intrinsic and extrinsic motivations, the participant of an adventure sport builds his/her perceptions. Perceptions can be different from the true attributes of the sport depending on how the individual receives and processes information. In other words, perceptions focus on the attributes of products that affect behavior and not on the real attributes of products. Perceptions are a cognitive measure of adventure sport value. This value represents the opportunity cost of the product (value for money), 
which means that perceptions are formed based on a cost benefit assessment.

Perception of an adventure sport may be analyzed from a cognitive or behavioral perspective. Perceptions are of several types: they can have a cognitive component (which results from the evaluation of the adventure sport attributes) and a personal component (that depends on how the individual intends to perceive that adventure sport).

Treks'n Rapids wanted to identify main motivational factors of attraction towards adventure sports among youths (the largest consumer segment) of National Capital Region. Objective was to improve the effectiveness of integrated marketing communications strategy.

Literature review: Of late there has been an upsurge in the adventure sport market. It includes soft adventure sports like camping, hiking, biking, bird-or-animalwatching, horseback riding, sailing, skiing and hard adventure vacations e.g., mountain biking, white water rafting, kayaking, scuba diving, rock climbing, snowboarding, skydiving. Hard adventure activities have been referred to as "risk recreation activities" which differs from traditional soft adventure activities because of the presence of significant components of risk (may be life threatening), danger and uncertainty, which could be either perceived or real (Ewert, 1994). Additionally, risk recreation activities include the following characteristics: (1) involvement with a natural environment, (2) elements of risk and, danger, (3) uncertain outcome and (4) influenced by the participant or circumstance.

Researchers have found the participation in risk recreation is a goal-driven behavior in which stimulation is sought for increasing arousal and/or to satisfy various other goals (Ewert, 1994).

Participants usually have multiple motives that differ in importance and are dependent upon their individual goals (Ewert, 1994). Mclntyre (1992) identified six factors: Recognition, Creativity, Physical Setting, Challenge, Escape and Control. Similarly, climbers at Mt. Rainer (Washington) were motivated to climb due to challenge, catharsis, recognition, creative opportunities, locus of control and the physical setting (Ewert, 1993); while climbers at Mt. McKinley (Alaska) noted five factors: Exhilaration/Excitement, Social Aspects, Image, Aspects of Climbing and Catharsis/Escape (Ewert, 1994).

While some research has attempted to elaborate the theories of sport behavior, including several factors that might possibly explain sport participation, other research has been focused on studying one of the factors more specifically, motivation to participate.
Several studies have demonstrated that the motives given for sport participation, i.e. the perceived benefits are not only the physical health aspects, but a number of other ones, such as weight control and appearance, stress and mood management, competition and enjoyment, fun and excitement.

Thus, there are differences between individuals in perceived benefits, which might explain some of the differences in sport participation. These perceptions of benefits, or motives to participate, are expected to be influenced by several factors, for example, age and gender.

If an experience of sport participation is perceived to be meaningful, a person will be more motivated to participate in such activities, but what is perceived as meaningful by one individual might not be perceived as such by another.

Gill (2000) attempted to measure the sport participants' motivations for youth. Eight motivation factors of sport participation were identified. The initial study showed that the most important reasons for participation were to improve skills, have fun, learn new skills, be challenged and be physically fit (Gill, 2000). Klint and Weiss (1986) used this measure with other youth sport samples and the results were consistent in several ways.

Weiss and Chaumeton (2008) cited three common threads. First, several factor analyses yielded consistent factors, including competence, fitness, affiliation, team aspects, competition and fun. Second, children and adolescents typically indicated that several motives were important. Third, there were minimal age, gender, experience and sport activity differences.

Dwyer (1992) sampled university students using a 5-point response format to examine the measure's internal structure. His resulting 6-factor structure (team orientation, achievement/status, fitness, friendship, skill development and fun/excitement/challenge) was similar to the results with youth samples. Important motives for participating were to maintain fitness; experience fun, excitement and challenge; and acquire and improve skills-findings consistent with the youth literature (Gill, 2000; Klint and Weiss, 1986). The least important reasons were friendship-oriented, achievement/statusoriented and team-oriented factor; these vary from the results with youth.

Many studies about participation motivation are found in the literature (Gill, 2000; Klint and Weiss 1986). Also many researchers have studied the motivation to participate in riskier adventure sports (Albert, 1999; Robinson, 1992; Thapa et al., 2005; Schuett, 1993; Wang et al., 2004; Weiss and Chaumeton, 2008). 
Statement and importance of the problem: Treks'n Rapids has been spending huge amount of money to set up new facilities for adventure sports in India. Thus it is important to plan these spending well as per the requirement of the customers and also to promote them effectively. It is a step to deliver products and services better suited to customer needs. Further, in this competitive and growing sector of adventure sports in India, it becomes necessary to develop and innovate to stay ahead of others and to compete. Also, as the company grows and matures, it is looking to establish its unique identity in adventure sports which is more recognized and focused.

Under the heat of intense competition from InMe type of firms in the organized sector and many competitors in unorganized sector, Treks'n Rapids has increased its marketing spends. But increasing promotion expenditure is not the solution; the firm must understand what to say (message content and structure) to the target market segment and how to reach out (media) cost effectively so that more adventure sport enthusiasts get attracted to Treks'n Rapids.

Through this study the firm wanted to identify the motivating factors towards adventure sports among the youths (between 18-35 years of age-considered to be the largest segment for adventure sports) residing in National Capital Region. This would help them in enhancing the effectiveness of their communication strategy.

Problems and issues: Scope of this study includes finding answers to following questions among young (between the age group of 18-35) male and female enthusiasts of adventure sports:

- What are the motivating factors that pull participants to adventure sports?

- Do different types of sports have significantly different pull factors?

- Do personal characteristics of participants affect the level of motivation?

- Is motivation level influenced by the characteristics of the sport?

- Based on identified motivating factors can the population be discriminated between male and female?

- Can we discriminate between high spenders and low spenders based on the identified motivating factors?

\section{MATERIALS AND METHODS}

To capture perceptions of youths, a questionnaire was designed and tested with twenty respondents and all problems encountered were removed.
Perceptions of respondents were captured on a seven point Likert Scale-with 1 being low and 7 being high. The questionnaire could capture perception of respondents for adventure sports as a whole as well as separately for each of the four types of sports viz., mountain sports; extreme sports; rafting and kayaking; paragliding, sky diving and skiing. Whether the respondent is aware about a particular type of sport or not has been checked by screening questions. For a particular sport responses of only those people were analyzed who were aware of the sport.

The questionnaire was designed in Google docs where links were posted to various mails and forums for review of people and filling up. It was put with a 7 day window period and after that responses were analyzed. The online survey removes the surveyor bias. Other advantage is that the data can be directly fed into excel sheet for analyses. Online survey also ensures random sampling. The link for the questionnaire was mailed to about 500 people out of whom 57 relevant (from youth) responses were obtained.

Data analyses: The motivational factors identified through exploratory studies are in Table 1.

Reliability test (t-test) for each question: This test helps in determining whether a question is well understood and it is able to distinguish between two classes of respondents: One who wish to 'Rate High' and the other who wish to 'Rate Low'. For such questions the null hypothesis of a two tailed t-test should get rejected when applied to test if there is any significant difference between the mean responses of top quartile and the bottom quartile of respondents in an ordered list. The null hypothesis for each question in the questionnaire was rejected at 0.05 level of significance. Hence analyses were carried out with all the questions.

Table 1: Motivational factors for adventure sports

Provides thrill

Requires zeal/energy

Spells status

Builds confidence

Helps in personality development

Instills self-belief

Creates unique identity

Is a stress buster

Helps in goal-setting

Is challenging

Requires toughness

Builds sense of achievement

Is a unique experience

It is fun/adventure

Improved technology has reduced risk 
Am. J. of Economics and Business Administration 2 (2): 172-178, 2010

Table 2: Cronbach's alpha, KMO and Bartlett's test

\begin{tabular}{llllll}
\hline Sports type & No. of respondents & No. of valid cases & Cronbach's alpha & KMO of sampling adequacy & Bartlett's test of sphericity \\
\hline Mountain & 51 & 46 & 0.917 & 0.818 & Reject H0 \\
Kayaking & 32 & 29 & 0.944 & 0.739 & Reject H0 \\
Extreme & 40 & 39 & 0.947 & 0.824 & Reject H0 \\
Paragliding & 37 & 34 & 0.932 & 0.773 & Reject H0 \\
Adventure & 57 & 57 & 0.874 & 0.810 & Reject H0 \\
\hline
\end{tabular}

Table 3: Factor analysis and identification of dimensions

\begin{tabular}{|c|c|c|c|c|}
\hline \multirow[b]{2}{*}{ Sports type } & \multirow{2}{*}{$\begin{array}{l}\text { No. of factors } \\
\text { extracted }\end{array}$} & \multirow{2}{*}{$\begin{array}{l}\text { Total variations } \\
\text { explained }\end{array}$} & \multicolumn{2}{|l|}{ Alignment of factors } \\
\hline & & & Dimension 1 & Dimension 2 \\
\hline Mountain & Two & 60.33 & $5,6,15,4,7,9,3$ and 13 & $1,2,14,8,10,11$ and 12 \\
\hline Kayaking & Two & 70.23 & $5,4,6,9,7,15,11,2$ and 3 & $14,1,13,12,8$ and 10 \\
\hline Extreme & Two & 71.44 & $6,4,5,7,9,3,15$ and 8 & $1,10,13,14,11,2$ and 12 \\
\hline Paragliding & Two & 66.34 & $6,7,9,15,5,4,12,8,14$ and 3 & $11,13,1,2$ and 10 \\
\hline Adventure & Two & 56.56 & $7,6,5,9,4$ and 3 & $14,13,10,15,1,12,2,8$ and 11 \\
\hline
\end{tabular}

Reliability of data captured: Summated scales are often used in survey instruments to probe underlying constructs that the researcher wants to measure. These may consist of indexed responses to dichotomous or multi-point questions, which are later summed to arrive at a resultant score associated with a particular question. The question of reliability arises as the function of scales is stretched to encompass the realm of prediction. One of the most popular reliability statistics in use today is Cronbach's alpha. It determines the internal consistency or average correlation of items in a survey instrument to gauge its reliability.

Table 2 displays the number of respondents obtained for each type of sports and for the adventure sport as a whole. Cronbach Alphas in all five cases are more than 0.874 indicating that reliability is high.

Validity test for questionnaire: Analyses were done first for each of the four types of sports. In Factor Analysis only two composite variables (dimensions) were extracted. The alignments of fifteen variables were noted and these were compared with the composite variables extracted for the combined responses of all 57 respondents to question number 10 . These five alignments were found to be highly consistent (Table 3). This establishes the validity of the questionnaire.

\section{RESULTS}

KMO and Bartlett's test of sphericity: In each case $\mathrm{KMO}$ is found to be more than 0.7 and the null hypothesis for Bartlett's test is rejected. This implies that the observed correlation matrix in each case is significantly (at 0.05 level of significance) different than an identity matrix. Hence data reduction can be carried out.
Table 4: Rotated component matrix ${ }^{\mathrm{a}}$

\begin{tabular}{|c|c|c|}
\hline \multirow[b]{2}{*}{ (For adventure) } & \multicolumn{2}{|c|}{ Component } \\
\hline & 1 & 2 \\
\hline 14. It is fun/adventure & 0.870 & -0.034 \\
\hline 13. Is a unique experience & 0.828 & 0.109 \\
\hline 10. Is challenging & 0.770 & 0.359 \\
\hline 15. Improved technology has reduced risk & 0.711 & 0.072 \\
\hline 1. Thrill & 0.684 & -0.044 \\
\hline 12. Builds sense of achievement & 0.629 & 0.473 \\
\hline 2. Requires zeal/energy & 0.598 & 0.421 \\
\hline 8. Is a stress buster & 0.592 & 0.091 \\
\hline 11. Requires toughness & 0.591 & 0.497 \\
\hline 7. Creates unique identity & 0.043 & 0.784 \\
\hline 6. Instills self-belief & 0.285 & 0.768 \\
\hline 5. Helps in personality development & 0.285 & 0.753 \\
\hline 9. Helps in goal-setting & 0.080 & 0.695 \\
\hline 4. Builds confidence & 0.511 & 0.552 \\
\hline 3. Spells status & -0.202 & 0.429 \\
\hline
\end{tabular}

Note: Extraction method: Principal component analysis; Rotation method: Varimax with Kaiser normalization; ${ }^{\text {a: }}$. Rotation converged in 3 iterations

Factor analysis and total variance explained: In each of the five cases (Adventure, Mountain, Kayaking, Extreme and Paragliding) two factors were extracted. The total variance explained is more than $56 \%$ in each case (Table 3).

The rotated component matrix of Factor analysis as applied to question number 10 is reproduced in Table 4.

The composite variables as indicated by the two dimensions (Fig. 1) have been labeled as:

- Characteristics of the self like: Building confidence, personality development, sense of achievement, status, self-belief and help in goal setting

- Characteristics of the adventure sports encompassing: Thrill, challenge, fun, toughness and zeal required 
Am. J. of Economics and Business Administration 2 (2): 172-178, 2010

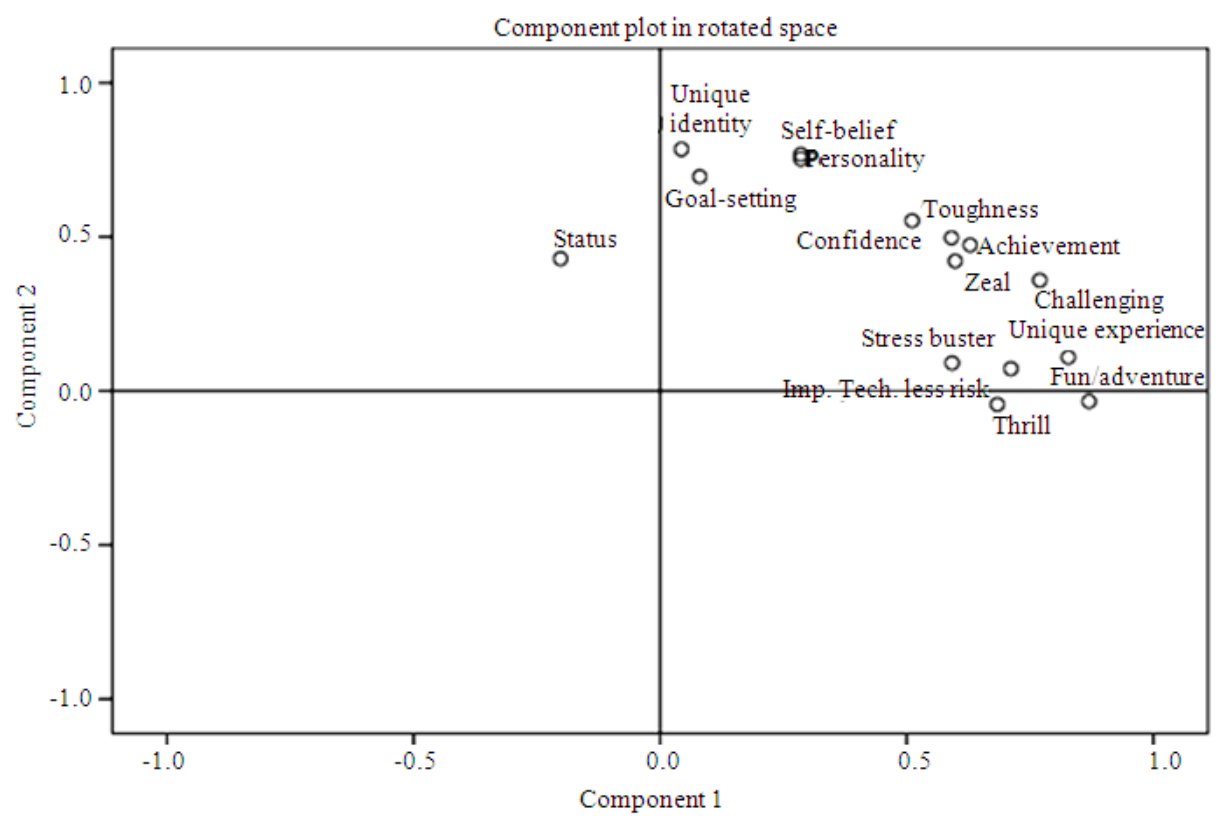

Fig. 1: Factor loading on two components (dimensions)

Based on the identified factors, the population was successfully discriminated on the basis of two separate categorical variables namely, gender and spending pattern of participants. In the analysis over $73 \%$ in case of gender (77\% in case of spending) of original grouped cases have been correctly classified.

\section{DISCUSSION}

This study establishes that all the fifteen factors as identified by previous researches contribute towards building motivation for the adventure sports.

It further suggests that factors influencing the motivation to participate do not differ for adventure sports such as Mountain sports, Kayaking, Extreme Sports and Para Gliding.

The participation in adventure sport is influenced by two factors: Characteristics of self and the Characteristics of the sport.

\section{CONCLUSION}

This study has brought out that the adventure sport enthusiasts are concerned about two factors:

- They feel that participation in adventure sports will help in building confidence; developing personality; enjoying the sense of achievement; displaying status; developing increased self-belief and in goal setting
- They expect that the adventure sport should provide thrill, challenge and fun. It should pose tough situation and should require high level of enthusiasm for participation

Accordingly, in order to attract participants, the firm Treks'n Rapids should design communication messages highlighting these two aspects.

Limitations: The respondents are residents of NCR regions only. This study needs to be replicated at other areas to increase external validity. The target segment selected was only youth. However, people of other age groups also get attracted to adventure sports. Their motivation factors also need to be studied. Further, it is felt that the motivation factors may differ between male and female respondents.

\section{REFERENCES}

Albert, E., 1999. Dealing with danger: the normalizations of risk in cycling. Int. Rev. Sociol. Sport, 34: 157-171. DOI: $10.1177 / 101269099034002005$

Dwyer, J.J.M., 1992. Internal structure of participation motivation questionnaire completed by undergraduates. Psycholog. Rep., 70: 283-290. http://search.ebscohost.com/login.aspx?direct=true $\& \mathrm{db}=\mathrm{bth} \& \mathrm{AN}=9204130194 \&$ site $=$ ehost-live 
Ewert, A., 1993. Differences in the level of motive importance based on trip outcome, experience level and group type. J. Leisure Res., 25: 335-349. http://search.ebscohost.com/login.aspx?direct=true $\& \mathrm{db}=\mathrm{bth} \& \mathrm{AN}=9406200132 \&$ site$=$ ehost-live

Ewert, A., 1994. Playing the edge: Motivation and risk taking in a high-altitude wilderness like environment. Environ. Behav., 26: 3-24 DOI: 10.1177/0013916594261001

Gill, D.L., 2000. Psychological Dynamics of Sport and Exercise. 2nd Edn., Human Kinetics, Champaign, IL., ISBN: 13: 978-0873229562.

Klint, K.A. and M.R. Weiss, 1986. Dropping in and dropping out: Participation motives of current and former youth gymnasts. Can. J. Applied Sport Sci., 11: 106-114. PMID: 3731373

Mclntyre, N., 1992. Involvement in risk recreation: A comparison of objective and subjective measures of engagement. J. Leisure Res., 24: 64-71. http://search.ebscohost.com/login.aspx?direct=true $\& \mathrm{db}=\mathrm{bth} \& \mathrm{AN}=9202171533 \&$ site $=$ ehost-live

Robinson, D., 1992. A descriptive model of enduring risk recreation involvement. J. Leisure Res., 24: 52-63.

http://search.ebscohost.com/login.aspx?direct=true $\& \mathrm{db}=\mathrm{bth} \& \mathrm{AN}=9202171532 \&$ site $=$ ehost-live
Schuett, M., 1993. Refining measures of adventure recreation involvement. Leisure Sci., 15: 205-216. DOI: 10.1080/01490409309513200

Thapa, B., A.R. Graefe and L.A. Meyer, 2005. Moderator and mediator effects of scuba diving specialization on marine-based environmental knowledge-behavior contingency. J. Environ. Educ., 37: 53-67. DOI: 10.3200/JOEE.37.1.53-68

Wang, C.K.J., R.P. Ang, S.M. Teo-Koh and A. Kahlid, 2004. Motivational predictors of young adolescents' participation in an outdoor adventure course: A self-determination theory approach. J. Advent. Educ. Outdoor Learn., 4: 57-65. DOI: 10.1080/14729670485200421

Weiss, M.R. and N. Chaumeton, 2008. Motivational Orientations in Sport. In: Advances in Sport Psychology, Horn, T. (Ed.). Human Kinetics, Champaign, IL., ISBN: 13: 978-0736057356, pp: 61-99. 